' Brown, W K G, and MacMillan, R L, in Textbook of Coronary Care, ed L E Meltzer, and A J Dunning, p 52. Amsterdam, Excerpta Medica, 1972

${ }^{8}$ McNeilly, R H, and Pemberton, J, British Medical fournal, 1968, 3, 139.

9 Baxter, S, British fournal of Hospital Medicine, 1974, 11, 875.

10 Bishop, L F, and Reichert, P, Psychosomatics, 1969, 10, 189.
11 Waddell, G, et al, British Medical fournal, 1975, 1, 386.

12 Lawrie, D M, et al, Lancet, 1967, 2, 109.

${ }^{13}$ Restieaux, N, et al, Lancet, 1967, 1, 1285.

14 Colling, A, British Medical fournal, 1974, 1, 559.

15 Council of the Royal College of General Practitioners, Fournal of the Royal College of General Practitioners, 1974, 24, 829.

\title{
Emergency arteriography in acute gastrointestinal bleeding
}

\author{
J D IRVING，T C NORTHFIELD
}

Some of the above criteria are unreliable or insensitive indicators of active bleeding. Melaena stools continue long after bleeding had stopped, and haemoglobin and packed cell volume do not fall till haemodilution has occurred. Only about half of the patients have a haematemesis at the time of an episode of recurrent haemorrhage, ${ }^{6}$ and central venous pressure is a more sensitive index of recurrent haemorrhage than pulse rate and blood pressure. ' Our main aim was to determine the diagnostic yield from arteriography carried out during active bleeding, making use of sensitive and reliable indicators of recurrent haemorrhage. Thus patients with acute gastrointestinal bleeding were routinely admitted to an intensive care ward and central venous pressure was measured hourly in addition to other forms of monitoring.

An additional objective was to carry out a pilot study of the potential therapeutic value of intra-arterial infusion of vasoconstrictors, as judged by the same sensitive and reliable indicators of recurrent haemorrhage. After the introduction of this form of treatment, ${ }^{8}$ Rosch et $a l^{9}$ clearly showed, by repeating arteriography immediately after intra-arterial adrenaline infusion, that it results in arterial vasoconstriction and the immediate stopping of haemorrhage from arteries in the upper gastrointestinal tract. It is not clear, however, what risk there is of recurrent haemorrhage over a longer period once the infusion has been stopped.

\section{Patients and methods}

Patients with acute gastrointestinal bleeding were admitted to an intensive care ward and selected for emergency arteriography if they fulfilled one or more of the following criteria: (1) haematemesis; (2) a fall in central venous pressure over two hours or less from $1 \mathrm{~cm}$ water above the manubriosternal joint to $4 \mathrm{~cm}$ water below the manubriosternal joint; (3) a rise in pulse rate of 20 beats/min over less than two hours; (4) a fall in systolic blood pressure of $20 \mathrm{~mm} \mathrm{Hg}$ over two hours or less; (5) gastric aspiration of fresh blood.

Diagnostic studies-Emergency arteriography was carried out within two hours of the patient fulfilling the above criteria. The coeliac artery, and in some cases the superior mesenteric artery, was catheterised from the femoral artery by the Seldinger technique. When evidence of bleeding was equivocal selective catheterisation of the left gastric or gastroduodenal artery was carried out as indicated.

Therapeutic studies-In the latter part of the study, when arteriography showed definite evidence of a bleeding site it was followed immediately by intra-arterial infusion of adrenaline or vasopressin. If immediate surgery was planned the infusion was given down the same catheter, but if not, then, to prevent clotting in the catheter tip, the original catheter, which had an end hole and a side hole, was changed for one having an end hole only, which was left in situ for 24-72 hours. For infusion of the coeliac axis adrenaline was given at a rate of $15-20 \mu \mathrm{g} / \mathrm{min}$ for $20-60$ minutes using a Fenwal pressure infusor. For infusion of the superior mesenteric artery vasopressin was given at a rate of 0.2 unit/min for 10 minutes, followed by 0.3 unit/ min for 20 minutes. ${ }^{10}$ After either infusion heparin was given slowly intravenously to keep the catheter patent. If further haemorrhage occurred the patient underwent emergency surgery preceded by a further infusion of adrenaline or vasopressin to prevent further preoperative blood loss.

Lewisham Hospital, London SE13 6LH
J D IRVING, MB, DMRD, consultant radiologist

T C NORTHFIELD, MD, MRCP, senior medical registrar, Lewisham and Guy's Hospitals (present address: St George's and St James's Hospitals, London) 


\section{Results}

\section{DIAGNOSTIC STUDIES}

During 1 December 1970 to 1 December 1973 arteriography was carried out successfully on 35 patients. Thirty-one patients underwent arteriography within two hours after fulfilling one or more of our criteria. Four patients did not strictly fulfill any of the criteria within the two hours before arteriography. A definite site of bleeding was identified by arteriography in 27 patients, a probable site in three, and no bleeding site in five. Of the latter five patients, one had had a frank haematemesis within the previous two hours, in three the presence of fresh blood on gastric aspiration was the only positive indication of active bleeding, and the fifth fulfilled none of the criteria. None of the five had any haemodynamic disturbance as indicated by a diagnostic change in pulse rate, blood pressure, or central venous pressure. All patients showing these changes, or having a frank haematemesis, had a positive arteriogram.

In three cases a vascular abnormality was found on arteriography, being in the duodenum in two cases, and in the upper jejunum in the third. In a further 13 patients the bleeding site was shown to be the duodenal cap, and in nine definite cases and three probable cases it was localised to some part of the stomach. In one patient it was localised to the region of a gastroenterostomy stoma, and in another to the lower oesophagus. Fig 1 shows dye in a deformed duodenal cap, and fig 2 dye flowing into a posterior-wall chronic gastric ulcer. Of the 30 patients having a definite or probable bleeding site identified by arteriography, 23 underwent emergency surgery. In 20 patients

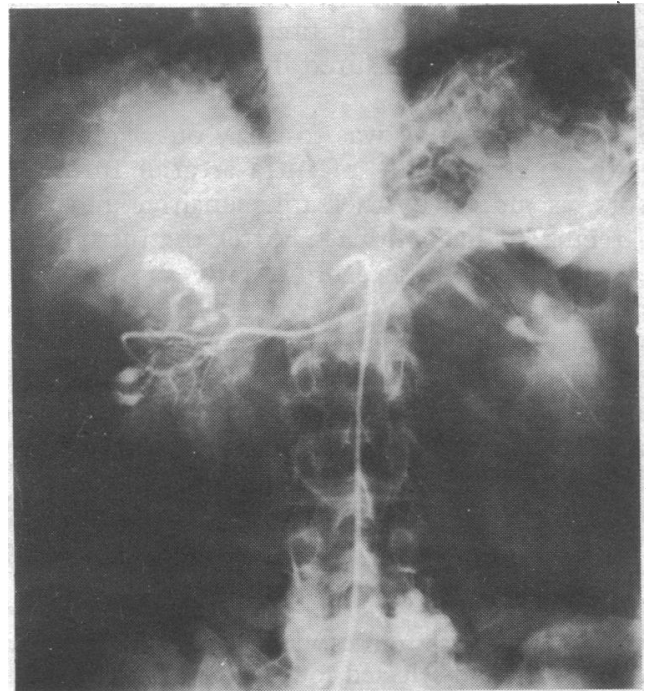

FIG 1-Coeliac arteriogram showing leak of dye into deformed duodenal cap.

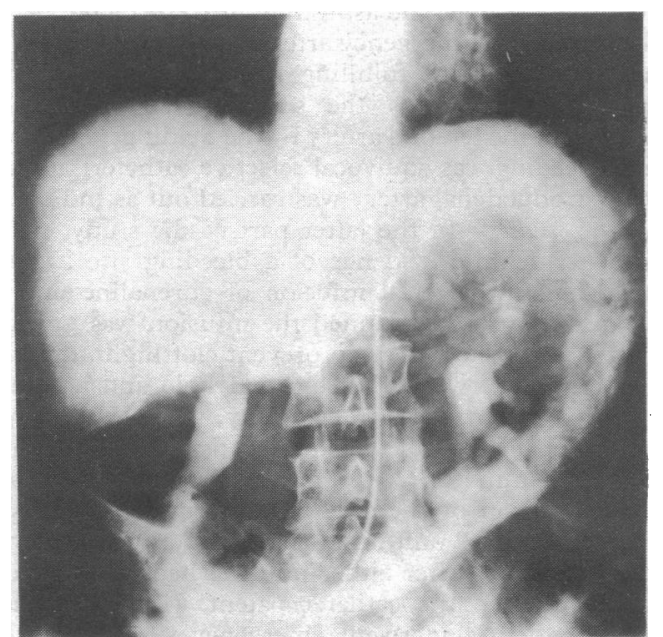

FIG 2-Leak of dye into posterior-wall chronic gastric ulcer. this provided confirmation of the site of bleeding. No abnormality was found at operation in the patient with a duodenal vascular abnormality or in another patient with a definite duodenal bleeding site. One patient thought from the arteriogram to have a probable but not definite gastric leak was found at operation to have a chronic duodenal ulcer and no detectable gastric lesion. This may represent a false-positive result.

\section{THERAPEUTIC STUDIES}

Seventeen of the last 19 patients undergoing arteriography were given an intra-arterial drug infusion immediately afterwards; 16 received adrenaline, and one, who was bleeding from a jejunal angioma supplied by the superior mesenteric artery, vasopressin. ${ }^{10}$ In seven patients the infusion was a temporary measure to facilitate preoperative resuscitation. In the six patients given adrenaline no active bleeding was found at operation, which was carried out within an hour of the arteriogram, but in the patient given vasopressin active bleeding was still present at operation.

In 10 patients, seven of whom had a chronic ulcer, intra-arterial adrenaline infusion was given a trial as definitive treatment. After the infusion the patients were monitored in the intensive care ward according to the same protocol as before treatment. In four patients with a chronic ulcer these observations showed evidence of a further episode of recurrent haemorrhage 5-68 hours (mean 29 hours) after the infusion. Emergency surgery was then carried out to stop the bleeding. In six patients there was no further evidence of active bleeding.

In one patient catheterisation failed because a wide and tortuous abdominal aorta prevented entry into the coeliac artery. The only serious complication attributable to arteriography or arterial infusion was in a man aged 69 who had gross iliac artery atheroma, ischaemic heart disease, and cardiac failure. Catheterisation and arterial infusion were carried out only because he was thought to be a poor surgical risk and had severe recurrent haemorrhage. He developed gangrene of one leg during a period of hypotension several hours after removal of the catheter from the femoral artery on that side. He had a Polya gastrectomy to stop continued bleeding from a chronic duodenal ulcer and died of bronchopneumonia eight days later.

\section{Discussion}

The use of sensitive and reliable criteria for diagnosing recurrent haemorrhage enabled a definite bleeding site to be identified by arteriography in 27 of the 35 patients, and a probable bleeding site in three. This study confirmed the results of a previous one in showing the reliability of central venous pressure measurements as a method of diagnosing recurrent haemorrhage, provided that the criteria for this diagnosis are carefully defined."

Arteriography gave a much higher diagnostic yield than is usually found with emergency barium-meal examination, which cannot detect acute ulcers. The diagnostic yield with arteriography was similar to that reported $(80 \%)$ for oesophagogastroduodenoscopy using end-viewing fibrescopes." A major advantage of arteriography over the barium meal is that it indicates the site of bleeding rather than a lesion that might have bled. To a large extent this advantage is shared by endoscopy, since Cotton et al l11 $^{11}$ found that $79 \%$ of ulcers seen on endoscopy showed unequivocal evidence of recent bleeding. This is important, since they reported that $32 \%$ of patients were found at endoscopy to be bleeding from a different lesion from the one diagnosed by barium meal. A disadvantage of arteriography is that it often fails to indicate the nature of the bleeding lesion, but in three of our patients arteriography showed a bleeding small-intestinal vascular abnormality, which would not have been identified by endoscopy or barium meal.

Diagnostically, arteriography and endoscopy may be regarded as complementary, whereas a prior barium meal prevents early effective examination by both endoscopy and arteriography and will probably become obsolete in the emergency investigation of acute gastrointestinal bleeding. ${ }^{11}$ Endoscopy is easier in the patient who is not actively bleeding, and an adequate examination may be impossible in the few patients who are bleeding profusely, ${ }^{11}$ whereas arteriography is of value only in the patient 
who is actively bleeding. If no lesion is found at endoscopy $(20 \%),{ }^{11}$ or if it is not clear that an ulcer seen on endoscopy is the site of bleeding (a further $\left.20^{\circ}{ }_{0}\right)^{11}$ then arteriography may be carried out if and when there is evidence of further active bleeding.

It has been shown ${ }^{8}$ that arterial drug infusion is effective in the short term in stopping haemorrhage in most cases, as judged by repeat arteriography immediately after stopping the infusion. Our results suggest that it may be of value in aiding resuscitation before surgery, since there was no active bleeding in six out of seven patients treated in this way. Several of these patients were bleeding severely, and the improvement in their clinical condition after drug infusion accompanied by continuing blood transfusion was striking.

The role of arterial drug infusion as a definitive treatment for acute gastrointestinal bleeding is dubious. There was no clinical evidence of a recurrence of bleeding in six out of 10 patients so treated. Probably, however, this proportion of patients would have shown no evidence of further bleeding in the absence of vasoconstrictor infusion. Seven of the 10 patients who received a trial of drug infusion as definitive treatment had a chronic ulcer, and these included the four patients in whom bleeding recurred. The results of Rosch et al ${ }^{10}$ agree with ours in sug- gesting that this treatment is of dubious value in such patients. Disappointing results have also been reported in patients bleeding from oesophageal varices. ${ }^{12}$ On the other hand, encouraging results ${ }^{1013}$ have been reported in patients with acute lesions, and further studies, preferably in the form of a controlled clinical trial, seem warranted in this group of patients.

\section{References}

1 Nusbaum, M, and Baum, S, Surgical Forum, 1963, 14, 374.

${ }^{2}$ Baum, S, et al, Surgery, 1965, 58, 797.

${ }^{3}$ Reuter, S R, and Bookstein, J J, Gastroenterology, 1968, 54, 876.

4 Frey, C F, Reuter, S R, and Bookstein, J J, Surgery, 1970, 67, 548.

5 Stanley, R J, and Wise, L, Archives of Surgery, 1973, 107, 138.

${ }^{6}$ Northfield, T C, and Smith, T, Lancet, 1971, 1, 990.

${ }^{7}$ Northfield, T C, and Smith, T, Lancet, 1970, 2, 584.

${ }^{8}$ Nusbaum, M, Baum, S, and Blackmore, W S, Annals of Surgery, 1969, $170,506$.

${ }^{9}$ Rosch, J, et al, Gastroenterology, 1970, 59, 341.

${ }^{10}$ Rosch, J, Dotter, C T, and Antonovic, R, American fournal of Roentgenology, 1972, 116, 279.

11 Cotton, P B, et al, British Medical fournal, 1973, 2, 505.

12 Murray-Lyon, I M, et al, Gut, 1973, 14, 59.

13 Athanasoulis, C A, et al, New England fournal of Medicine, 1974, 290, 597.

\title{
Plasma cyclic adenosine- $3^{\prime}, 5^{\prime}$-monophosphate response to glucagon in patients with liver disease
}

\author{
TERRY F DAVIES, KEN PRUDHOE, ADRIAN P DOUGLAS
}

British Medical Fournal, 1976, 1, 931-933

\section{Summary}

The change in plasma cyclic adenosine-3', 5'-monophosphate (AMP) was measured after intravenous injection of $1 \mathrm{mg}$ of glucagon in 10 normal subjects and 30 patients with various forms of liver disease. Patients with cirrhosis and those with intrahepatic cholestasis responded normally but in patients with extrahepatic obstruction the plasma cyclic AMP response was considerably increased. Six of the eight patients with cirrhosis and a surgically created portacaval shunt had very reduced responses. This test may prove to be diagnostically important, particularly in differentiating surgical from non-surgical jaundice.

\section{Introduction}

Glucagon increases the plasma concentration level of cyclic adenosine- $3^{\prime}, 5^{\prime}$-monophosphate (AMP), ${ }^{12}$ and the source of this nucleotide is primarily the liver. ${ }^{2}{ }^{3}$ It therefore seemed likely that this response would be impaired in liver disease and that such studies might yield a diagnostically useful test. We studied the plasma cyclic AMP response to intravenously administered glucagon in normal subjects and those with liver

\footnotetext{
Department of Medicine, Royal Victoria Infirmary, Newcastle upon Tyne NE1 4LP

TERRY F DAVIES, MB, MRCP, senior research associate KEN PRUDHOE, BSC, PHD, biochemist

ADRIAN P DOUGLAS, MD, MRCP, consultant gastroenterologist
}

disease to see how the response differed in various types of hepatic disorder.

\section{Subjects and methods}

All subjects were selected randomly as they presented in the clinic. Informed consent was always obtained and the study was approved by the hospital ethical committee. Ten volunteers from the medical staff were studied for control data. All had normal results on standard liver function tests and no history of liver disease. The following patients were studied: 10 patients with established cirrhosis of differing aetiology and severity, none of whom had encephalopathy (they included two with portal hypertension); a further eight patients with cirrhosis who had had shunt surgery from six months to eight years earlier; and 12 patients with cholestatic jaundice, of whom six had severe extrahepatic large duct obstruction and the remaining six had intrahepatic cholestasis (one hepatitis A, three drug jaundice, two sclerosing cholangitis). Table I summarises the liver function test results in these subjects.

After fasting from midnight a cannula was inserted into a peripheral arm vein between $8 \mathrm{am}$ and $10 \mathrm{am}$. Basal venous samples were

TABLE I-Results of liver function tests in groups studied

\begin{tabular}{|c|c|c|c|c|c|}
\hline & $\begin{array}{c}\text { No } \\
\text { of } \\
\text { subjects }\end{array}$ & $\begin{array}{c}\text { Mean } \\
\text { age } \\
\text { (years) }\end{array}$ & $\begin{array}{c}\text { Mean } \\
\text { aspartate } \\
\text { amino- } \\
\text { transferase } \\
\text { (normal } \\
\text { 4-20 IU } / 1 \text { ) }\end{array}$ & $\begin{array}{c}\text { Mean } \\
\text { alkaline } \\
\text { phosphatase } \\
\text { (normal } \\
20-90 \mathrm{IU} / \mathbf{l})\end{array}$ & $\begin{array}{c}\text { Mean } \\
\text { bilirubin } \\
(\text { normal } \\
1 \cdot 7-17 \mu \mathrm{mol} / \mathrm{l})\end{array}$ \\
\hline \multirow{4}{*}{$\begin{array}{l}\text { Controls ... } \\
\text { Patients with: } \\
\text { Cirrhosis } \\
\begin{array}{c}\text { Portacaval shunts } \\
\text { Extrahepatic } \\
\text { obstructive } \\
\begin{array}{c}\text { jaundice } \\
\text { Intrahepatic } \\
\text { cholestasis }\end{array}\end{array} \text {.. }\end{array}$} & 10 & $27 \cdot 4$ & $12 \cdot 9$ & $46 \cdot 7$ & $7 \cdot 7$ \\
\hline & $\begin{array}{r}10 \\
8\end{array}$ & $\begin{array}{l}58 \cdot 2 \\
45 \cdot 0\end{array}$ & $\begin{array}{l}64 \cdot 2 \\
27 \cdot 0\end{array}$ & $\begin{array}{l}185.6 \\
146.0\end{array}$ & ${ }_{32.5}^{118}$ \\
\hline & 6 & $45 \cdot 2$ & $25 \cdot 2$ & $257 \cdot 0$ & 260 \\
\hline & 6 & $42 \cdot 6$ & $52 \cdot 6$ & 312.7 & 119 \\
\hline
\end{tabular}

Conversion: SI to traditional units-Bilirubin: $1 \mu \mathrm{mol} / 1 \approx 0.058 \mathrm{mg} / 100 \mathrm{ml}$. 